\title{
Heart failure with preserved ejection fraction; the other half of the heart failure, how it stands in 2013
}

\author{
Kunal Bikram Shaha*, Rikesh Tamrakar, Man Bahadur KC, Deewakar Sharma,Yadav Deo \\ Bhatt, Sujeeb Rajbhandari, Ranjit Sharma, Rabindra Simkhada \\ Department of Cardiology, Shahid Gangalal National Heart Centre,Kathmandu, Nepal
}

\section{Citation}

Shaha KB, Tamrakar R, KCMB, et al. Heart failure in with preserved ejection fraction; the other half of the heart failure, how it stands in 2013. Nepalese Heart Journal 2013;10(1):46-56.

\section{Keywords}

diastolic dysfunction, diastolic heart failure, heart failure with preserved ejection fraction

\begin{abstract}
Last two decade, heart failure with preserved ejection fraction was deprived from being considered as a part of spectrum of heart failure. May be heart failure with preserved ejection fraction was common but not recognized by cardiology fraternity. Heart failure with reduced ejection fraction and heart failure with preserved ejection fraction each make up about half of the overall heart failure burden. But the paradox is: morbidity and mortality in heart failure with preserved ejection fraction despite being similar to patients with heart failure with reduced ejection fraction, today's cardiology community has not much to offer in terms of mortality reducing treatment. The term diastolic heart failure has been well replaced by heart failure with preserved ejection fraction because multiple non-diastolic abnormalities in cardiovascular function also contribute to heart failure with preserved ejection fraction and diastolic dysfunction always accompanied heart failure with reduced ejection fraction. Diagnosis of heart failure with preserved ejection fraction is an uphill task since it relies upon careful clinical evaluation, doppler (pulse wave and tissue) echocardiography, and invasive hemodynamic assessment after exclusion of potential noncardiac causes of symptoms suggestive of heart failure. Patients with heart failure with preserved ejection fraction are usually older women with a history of hypertension. Obesity, coronary artery disease, diabetes mellitus, and atrial fibrillation are also highly prevalent in heart failure with preserved ejection fraction. Cornerstone of treatment of this entity revolves around treatment of underlying cause and symptom guided therapy.
\end{abstract}

\section{INTRODUCTION}

Last two decade, heart failure with preserved ejection fraction (HFpEF) was deprived from being considered as a part of spectrum of heart failure (HF). May be HFpEF was common but not recognized by cardiology community. The

\section{*Corresponding author}

Kunal Bikram Shaha

Department of Cardiology

Shahid Gangalal National Heart Centre,

Kathmandu, Nepal

Email: drshahakunal@hotmail.com 
term Diastolic heart failure has been abandoned and replaced by "HPpEF" 1,2 because multiple non-diastolic abnormalities in cardiovascular function also contribute to HPpEF and diastolic dysfunction always accompanied Heart failure with reduced ejection fraction (HFrEF).It was in late 70's and early 80's when it was unearthed that diastolic LV dysfunction importantly attributed to $\mathrm{HF}$ in hypertrophic cardiomyopathy, ${ }^{3,4}$ aortic stenosis, ${ }^{4,5}$ and hypertensive heart disease. ${ }^{6} \mathrm{HFpEF}$ came to limelight and was addressed in studies, which were a 'by-product' of the large HF trials investigating the use of angiotensin converting enzyme inhibitors (ACEIs) in HF with HFrEF and in post-infarct left ventricle (LV) remodeling. ${ }^{7,8,9}$

Several criteria have been proposed to define the syndrome of HFpEF. These include (a) clinical signs or symptoms of HF; (b) evidence of preserved or normal left ventricle ejection fraction (LVEF); and (c) evidence of abnormal left ventricle diastolic dysfunction that can be determined by Doppler echocardiography or cardiac catheterization. ${ }^{10}$ The diagnosis of HFpEF is more challenging than the diagnosis of HFrEF because it is largely one of excluding other potential noncardiac causes of symptoms suggestive of HF. Studies have suggested that the incidence of HFpEF is increasing and that a greater portion of patients hospitalized with $\mathrm{HF}$ have HFpEF. ${ }^{11}$

\section{The New Classification:}

The HFpEF syndrome includes following spectrum in accordance with the 2013 ACCF/AHA Guideline for the Management of Heart Failure: ${ }^{58}$

\begin{tabular}{|c|c|c|}
\hline Classification & $\begin{array}{l}\text { Ejection } \\
\text { Fraction }\end{array}$ & Description \\
\hline $\begin{array}{l}\text { II. Heart Failure with } \\
\text { Preserved Ejection } \\
\text { Fraction (HFpEF) }\end{array}$ & $\geq 50 \%$ & $\begin{array}{l}\text { Also referred to as diastolic HF. Several different criteria have } \\
\text { been used to further define HFpEF. The diagnosis of HFpEF is } \\
\text { challenging because it is largely one of excluding other potential } \\
\text { noncardiac causes of symptoms suggestive of HF. To date, } \\
\text { efficacious therapies have not been identified. }\end{array}$ \\
\hline a. HFpEF, Borderline & $41 \%$ to $49 \%$ & $\begin{array}{l}\text { These patients fall into a borderline or intermediate group. Their } \\
\text { characteristics, treatment patterns, and outcomes appear similar } \\
\text { to those of patient with HFpEF. }\end{array}$ \\
\hline b. HFpEF, Improved & $>40 \%$ & $\begin{array}{l}\text { It has been recognized that a subset of patients with HFpEF } \\
\text { previously had HFrEF. These patients with improvement or } \\
\text { recovery in EF may be clinically distinct from those with } \\
\text { persistently preserved or reduced EF. Further research is needed } \\
\text { to better characterize these patients. }\end{array}$ \\
\hline
\end{tabular}

\section{Statistics in HFpEF and Natural History:}

In patients with clinical HF, studies estimate that the prevalence of $\mathrm{HFpEF}$ is approximately $50 \%$ (range $40 \%$ to $71 \%) .{ }^{12}$ As per Ceia et al, (Figure $1 \mathrm{~A}, 1 \mathrm{~B}$ ): The prevalence of HF with a depressed and reduced LVEF increases with age but with pertinent rise in case of HFpEF. Female preponderance was noted in $\mathrm{HFpEF}$ in contrary to male preponderance in $\mathrm{HFrEF}$ as depicted below.
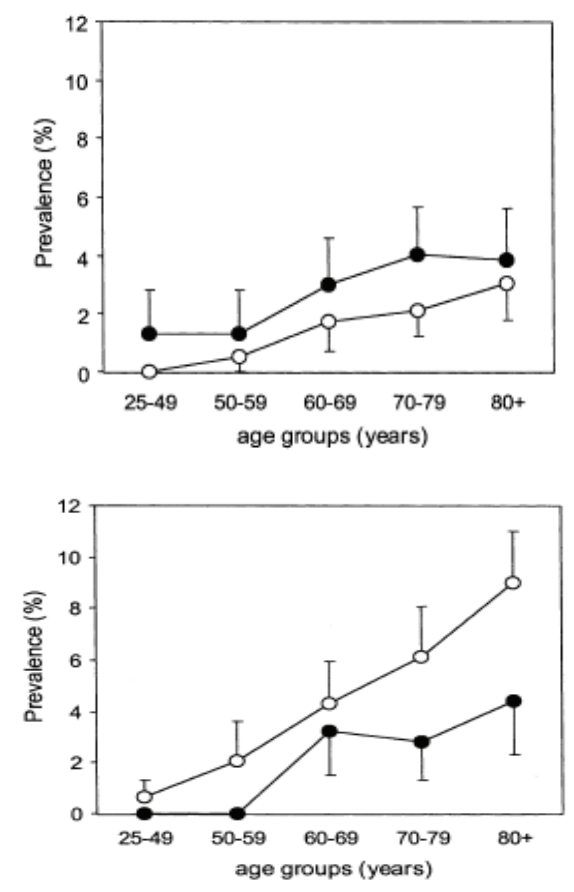

FIGURE 1A: The age- and gender-specific prevalence of $\mathrm{HFpEF}$

1B: The age- and gender-specific prevalence of HFrEF

(From Ceia, Fonseca, Mota, et al: Prevalence of chronic heart failure in Southwestern Europe: The EPICA study. Eur J Heart Fail 4:531, 2002.) 


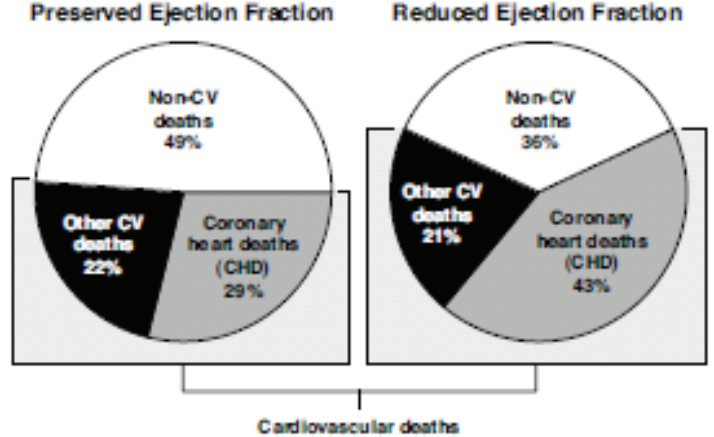

Figure 2: Cause of death in patients with HFpEF. (From Henkel DM, Redfield MM, Weston SA, et al. Death in heart failure: a community perspective. Circ Heart Fail. 2008;1:91.)

In two different studies conducted by Curtis et al ${ }^{17}$ and Henkel, et al ${ }^{18}$ a common inference can be well drawn that mortality in patients with HFpEF in comparison to the patients with HFrEF, attributed mainly to noncardiovascular causes.

As per Dunlay et al. ${ }^{19}$ comorbidities influence morbidity and mortality in patients with HFpEF. Smith et al., ${ }^{20}$ reported the lifetime burden of allcause hospitalization is high and nearly equivalent among patients with preserved or reduced EF with progressive functional decline after an admission for HF in either form of HF. The fact that HFpEF have morbidity and mortality similar to that of patients with HFrEF, has lead to multiple numerous research over curbing down natural history of HFpEF.

Demographics and Comorbidities ${ }^{13}$ :

Patients with HFpEF are generally older than 65 years, with many older than 80 years, and they are prominently although not predominantly women (50\% to $70 \%)$. A history of hypertension is present in most patients and may have developed only later in life. ${ }^{13}$ Obesity that owes adverse hemodynamic burden and pro-inflammatory state is seen in $30 \%$ to $50 \%$ of patients, diabetes in $30 \%$ to $50 \%$, and atrial fibrillation (being disease of old age and fellow traveler with hypertension) in up to $20 \%$ to $40 \%$. The prevalence of renal disease is high and similar to that noted in patients with HF and a reduced LVEF. The reported prevalence of coronary artery disease varies widely but is lower in HFpEF than in HF with reduced LVEF. Obstructive sleep apnea contributes to symptom severity and probably promotes progression of HF. Central sleep apnea can occur in association with severe HFpEF. Even in the absence of epicardial coronary disease, aging, hypertension, and diabetes are associated with vascular rarefaction and reduced coronary microvascular density, which can lead to impaired coronary flow reserve and diastolic dysfunction during stress further aided by worsened filling due to loss of atrial kick brought about by Atrial fibrilliation. ${ }^{13}$

\section{Why is it justified to classify HF spectrum into "HFrEF \& HFpEF"?}

It is not established whether HFpEF and HFrEF represent distinct forms of $\mathrm{HF}$ or exist as part of one 'HF spectrum', ${ }^{21}$ although the distinct patterns of chamber and myocellular remodelling observed coupled with disparate responses to medical therapies would all suggest that they are two discrete disease processes. The prevalence of HFpEF relative to $\mathrm{HFrEF}$ is rising at an alarming rate of $\sim 1 \%$ per year, thereby rapidly turning HFpEF into the most prevalent HF phenotype over the next decennium; yet in contrast to HFrEF, no improvements in outcome have been realized over the past two decades. ${ }^{12}$

\section{Pathophysiology}

It can be fairly divided into two broad abnormalities:

1. Diastolic abnormality $3,4,5,6,13$

a. Isovolumetric relaxation prolongation.

b. Slow LV Filling.

c. LV stiffness

2. Non Diastolic abnormality

a. Systolic dysfunction ${ }^{36,37}$ and exerciseexacerbated systolic dysfunction, ${ }^{22.23 .24,25}$

b. Impaired ventricular-vascular coupling, ${ }^{26,27,29,30}$

c. Neurohumoral Activation ${ }^{13}$

d. Abnormal exercise-induced and flow mediated vasodilation, ${ }^{24,25,26,27,34}$

e. Chronotropic incompetence, ${ }^{24,26,27,31}$ and

f. Atrial Dysfunction ${ }^{13}$

g. Pulmonary arterial hypertension..$^{32,33}$

\section{Diastolic abnormality: At Molecular Level}

\section{At the level of extracellular matrix:}

- Increase collagen (type 1) synthesis and decreased collagen degradation due to inhibition of metalloproteinases ${ }^{35}$,

- Increased collagen stiffness (advanced glycation end products). ${ }^{13}$

\section{Cardiomyocyte:}

a. Pressure overload $\rightarrow$ chronically increased catecholamine level $\rightarrow$ beta adrenergic stimulation $\rightarrow$ dowregulation of beta 
receptors $\rightarrow$ decrease in sarcoplasmic reticulum calcium ATPase activity further aided by depletion of $\mathrm{ATP} \rightarrow$ reduced uptake of calcium into sarcoplasmic reticulum $\rightarrow$ Increased diastolic calcium $\rightarrow$ lack of actin-myosin detachment $\rightarrow$ Incomplete and impaired relaxation. ${ }^{13}$

b. Titin is a giant elastic protein expressed in cardiomyocytes in two main isoforms, N2B (stiffer spring) and N2BA (more compliant spring). The N2BA:N2B isoform expression ratio is increased in eccentrically remodelled explanted hearts from dilated cardiomyopathy patients when compared with control donor hearts. Although titin-isoform switching is a confirmed mechanism for adjusting myocardial passive stiffness, recent studies suggested that the increased passive stiffness of failing myocardium can also arise from alterations in the phosphorylation state of titin or from the oxidative stress-induced formation of disulfide bridges within the titin molecule. A stiffness change within one compartment is also transmitted to the other compartment via matricellular proteins ${ }^{35}$.

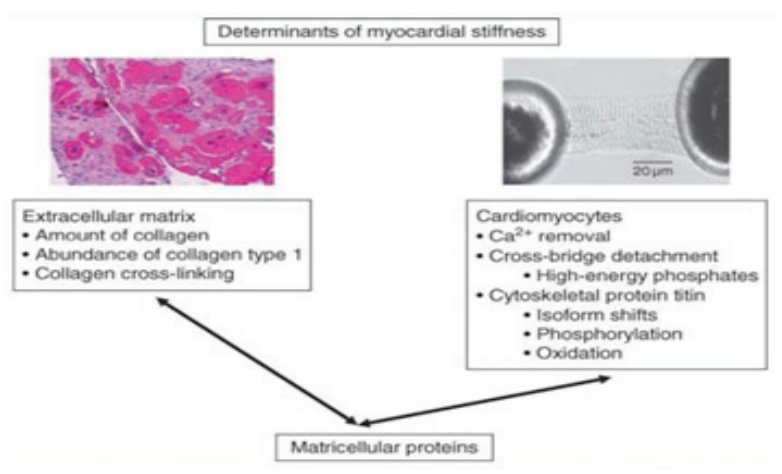

Figure 3: Determinants of myocardial stiffness ${ }^{35}$

Evidence of diastolic dysfunction : measured by invasive and non invasive methods:

a. Isovolumetric relaxation time (IVRT) Prolongation.

Measured invasively by "Tau" the time constant of relaxation described as rate of pressure decay during IVRT measured $>60$ msec in HFpEF at 70 beats/min of HR and increases to $86 \mathrm{msec}$ during exercise. ${ }^{13}$

b. Slow LV Filling.

Measured non-invasively by ${ }^{13}$

- ECHO using transmitral flow pattern(E,A),

- velocity of Lateral mitral annular ascent during early diastole(e') which is preload independent and correlates inversely with tau.

- $\quad \mathrm{E} / \mathrm{e}^{\prime}>15$ as raised LV filling pressure.

- Left atrial enlargement.

- Pulmonary hypertension due to chronic pulmonary venous hypertension due to raised left atrial pressure.

c. LV stiffness:

End-diastolic pressure-volume relationship (EDPVR) can be measured invasively using multiple beat method. ${ }^{13}$

\section{Non-Diastolic abnormalities contributing in HFpEF:}

a. Systolic dysfunction ${ }^{35,36,37}$ and exerciseexacerbated systolic dysfunction, ${ }^{22,23,24,25,35}$

Numerous studies have depicted depressed longitudinal ${ }^{36,37}$ and radial systolic function in $\mathrm{HFpEF}^{38}$ End-systolic elastance (Ees), defined by the slope and intercept of the endsystolic pressure-volume relationship, is a gold standard measure of chamber contractility that, in contrast to other measures, is elevated in HFpEF, ${ }^{39,40}$ suggesting enhanced contractility. Ees is elevated in HFpEF despite depressed contractility, measured using other contractile indices, across each pattern of ventricular chamber geometry. ${ }^{23}$ It is speculated that the same processes that promote diastolic ventricular stiffening in HFpEF also increase systolic stiffening and contribute to reduced myocardial contractility and limited systolic reserve. Systolic function is clearly not
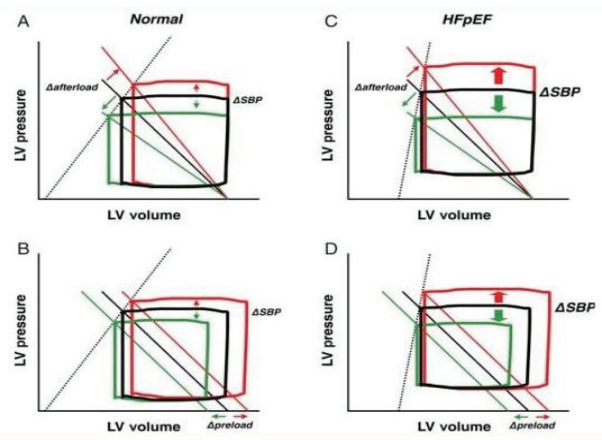

(Compared with normal controls (A and B), the slope of the end-systolic pressure-volume relationship (end-systolic elastance; Ees, dotted lines) is increased in HFpEF (C and D). This leads to exaggerated increase and decrease in blood pressure for the same change in afterload ( $A$ and $C)$ or preload ( $B$ and $D$ ) in $H F p E F$, accounting for the greater predilection for hypertensive crisis and/ or hypotension and azotemia with over-diuresis or overly vigorous vasodilation..$^{35}$ ) 
as impaired in $\mathrm{HFpEF}$ as in $\mathrm{HFrEF},{ }^{37}$ but recent studies have shown that even mild limitations in basal contractility in HFpEF may become more problematic in the setting of exercise stress, ${ }^{24,25,26,27,28}$ where an inability to enhance contractility may be associated with impaired cardiac output reserve, more severe symptoms of exercise intolerance, and reduced aerobic capacity.

b. Impaired ventricular-vascular coupling, $26,27,29,30,35$

Chronic changes in vascular stiffness are met by increases in LV systolic stiffness to maintain optimal ventricular-vascular matching and thus optimal cardiac performance. Whereas ventricular-vascular coupling helps maintain stroke volume and mechanical efficiency, increases in $\mathrm{E}_{\mathrm{es}}$ may have adverse effects. Increase in Ees indicate increased sensitivity of systolic pressure to changes in volume (as demonstrated by the steeper slope of the endsystolic pressure-volume relationship). Thus, volume overload in such individuals could be associated with greater increase in systolic blood pressure. Together, increase in arterial and systolic stiffness promote load-induced impairment in LV relaxation. Whereas coupling of vascular and ventricular systolic stiffness is preserved at rest in Heart failure with normal ejection fraction (HFnEF), such coupling may not be preserved during exercise. ${ }^{13}$

\section{c. Neurohumoral Activation ${ }^{13}$}

Neurohumoral activation plays a fundamental role in the progression of HF with reduced LVEF. Activation of the sympathetic nervous system, aldosterone, and the natriuretic peptide system occurs in HF regardless of LVEF, and although natriuretic peptide levels are lower in HFnEF, levels of catecholamines and aldosterone are similar in the limited study to date. Whether other counterregulatory hormones such as renin, angiotensin II, and endothelin are activated in HFnEF remains to be determined ${ }^{13}$.

\section{d. Abnormal exercise-induced and flow} mediated vasodilation ${ }^{24,25,2627,34}$ :

Vascular dysfunction in HFpEF may be due in part to endothelial dysfunction, as a recent study demonstrated impaired flow-mediated vasodilation in HFpEF compared with healthy age-matched controls. ${ }^{26}$ Symptoms of dyspnoea and fatigue in $\mathrm{HF}$ may be related to pathologic ergoreflex activation, which is also related to Nitric Oxide ( NO) bioavailability. ${ }^{41}$ Intriguingly, the extent of flow-mediated vasodilation (a biomarker of endothelial function) is related to the severity of symptoms of effort intolerance during low-level exercise in HFpEF, ${ }^{26}$ emphasizing the complex cross-talk between peripheral processes and perception of symptoms in $\mathrm{HF}^{42}$ These data provide further rationale for therapies targeting NO in HFpEF. ${ }^{35}$

e. Chronotropic incompetence and cardiovascular reserve dysfunction: ${ }^{24,26,27,31,35}$

The increased catcholamine level in HFpEF individuals leading to beta receptor downregulation further aided by the increased catecholamine level during exercise leading to increased diastolic calcium load coupled along with autonomic dysfunction may contribute to chronotropic incompetence, as baroreflex sensitivitys reduced and heart rate recovery impaired in HFpEF manifesting patient's exertional dyspnea into clinical picture.

\section{f. Atrial Dysfunction: 13}

Whereas Left Atrial (LA) systolic function compensates for reduced early filling in the earlier stages of $\mathrm{HFnEF}$, atrial failure eventually occurs. Indeed, an often forgotten hemodynamic hallmark of restrictive cardiomyopathy is the presence of large $V$ waves in the LA pressure waveform in the absence of mitral regurgitation, reflecting reduced LA compliance. Reduced LA compliance has been shown to potently influence the development of pulmonary arterial hypertension in mitral valve disease and may play a similar role in HFpEF. Reduced LA systolic function limits LV filling in the setting of impaired relaxation and necessitates higher mean LA pressures to augment early diastolic filling. Thus, enlarged and dysfunctional atria may contribute to the pathophysiologic process of $\mathrm{HFpEF}{ }^{13}$

\section{g. Pulmonary arterial hypertension: : $^{32,33}$}

Chronic venous pulmonary hypertension due to raised LA pressure as reflected interms of raised LV filling pressure translates into some degree of hypertension at the pulmonary arterial end further assisted by vascular endothelial dysfunction and age related stiffness. 


\section{Simple diagnostic algorithm of HFpEF:}

(Modified from Griffin ${ }^{43}$, 2013 ACCF/AHA Guidelines for Recommendations for Treatment of $\mathrm{HFpEF}^{58}$ )

Exertional Dyspnea / Symptoms \& Signs of Heart Failure not explained by non cardiac cause

$$
\downarrow
$$

Evidence of Preseved Ejection Fraction

- Classical HFpEF $>50 \%$,

- Borderline HFpEF 40-50\%,

- Improved (previously $<40 \%$ now improved to $>40 \%$ )

Evidence of Raised LV filling pressure (Any one of the following)

\section{Non Invasive}

$: \rightarrow$ E/e' $\quad$ E/e'>15(By pulse wave and TDI of lateral mitral annulus)

$\rightarrow$ E/e' $>8<15^{*}$ : LA enlargement/LA volume index $>40 \mathrm{ml} / \mathrm{m}^{2} \quad$ OR Raised NT-BNP $>220 \mathrm{pg} / \mathrm{mL}$ or $\mathrm{BNP}>200 \mathrm{pg} / \mathrm{mL}$

\section{Invasive:}

\section{$\rightarrow$ LVEDP $>16$ mmHg OR PCWP $>12 \mathrm{~mm} \mathrm{Hg}$}

*In contrast to recent critiques on the validity of $\mathrm{E} / \mathrm{e}^{\prime}$ as a measure of LV filling pressures in acutely decompensated HFrEF patients, ${ }^{44}$ a direct comparison of $\mathrm{E} / \mathrm{e}^{\prime}$ against conductance catheterderived diastolic LV stiffness moduli yielded a $83 \%$ sensitivity, a $92 \%$ specificity, and an area under the ROC curve of 0.907 for $E / \mathrm{e}^{\prime}>8$ as a measure of high-stiffness modulus in HFpEF patients. ${ }^{46}$ These findings suggested $\mathrm{E} / \mathrm{e}^{\prime}>8$ may be able to provide stand-alone evidence of diastolic LV dysfunction without further need of serial non-invasive tests in patients presenting with a $8<\mathrm{E} / \mathrm{e}^{\prime}<15 .{ }^{45}$

\section{Exercise testing in HFpEF:}

From diagnostic point of view Cardiopulmonary exercise testing (CPET) is useful in selected subset of HFpEF population where the cause is not quite obvious .Treatment of exercise-induced hypertension could be important part since exaggerated exertional hypertension can cause loaddependent diastolic dysfunction with raised LV filling pressure as aforementioned in the exercise induced pathophysiology in HFpEF. Chronotropic incompetence the other mechanism is also relatively common (higher than 20\%) in patients with HFpEF (although not more common than in HF with a reduced $\mathrm{EF}$ ), even in the absence of beta blocker therapy ${ }^{13 .}$ Henceforth, exercise testing can give a chance to see if a patient is chronotropically competent or not.

The diagnosis of HFpEF could only be made using exercise hemodynamic evaluation in such patients, although an abnormal increase in left heart pressure with leg raise (a marker of reduced diastolic reserve) was also a strong predictor of HFpEF. Pulmonary artery pressures track very closely with left heart filling pressures in early-stage HFpEF, ${ }^{34}$ suggesting that if the former could be accurately estimated by echocardiography during exercise, this may serve as a useful non-invasive screen among patients with normal EF and exertional dyspnoea. ${ }^{35}$

TDI-based evaluations during exercise, with early studies showing reasonable correlation with invasive measures. ${ }^{47}$ However, E/e' may be less robust in the setting of tachycardia, hyperventilation, and fusion of early and late transmitral filling velocities, as the variability in both numerator and denominator will be summed. The role of non-invasive diastolic stress testing in the evaluation of early $\mathrm{HFpEF}$ merits further study and validation, but at this time invasive evaluation provides more reliable diagnostic information ${ }^{35}$. In patients who do not meet established criteria for positive diagnosis of $\mathrm{HFpEF}^{13}$ but in whom there is reasonably strong clinical suspicion, invasive evaluation should be strongly considered, with exercise stress if available and resting measurements are unremarkable. ${ }^{34}$

CPET can also reveal poor motivation and pulmonary limitation as alternative explanation for dyspnea in patients with HF symptoms and normal LVEF. ${ }^{13}$

\section{Therapeutics trials and HFpEF:}

When we flip back in yesteryear's pages of evolution of HFpEF, we will be exclaimed to know that this entity got into limelight when a new subset of patients appeared clinically with heart failure signs and symptoms with preserved EF in large clinical trials examining HFrEF.

Till date with objectivity of benefiting the patients with HFpEF many trials, enlisted below, have been conducted but these trials failed to show any mortality reducing measures. 


\begin{tabular}{|c|c|c|}
\hline Trials & Result & Remark \\
\hline DIG Trial ${ }^{48}$ & $\begin{array}{l}\text { Digoxin did not alter the primary endpoint of HF } \\
\text { hospitalization or cardiovascular mortality but } \\
\text { did reduce HF hospitalizations }\end{array}$ & $\begin{array}{l}\text { The total cardiovascular hospitalizations } \\
\text { were not reduced because of an increased } \\
\text { rate of admissions for unstable angina, } \\
\text { which completely negated the beneficial } \\
\text { effect of reduced HF hospitalizations. } \\
\text { Observation of fewer HF }\end{array}$ \\
\hline $\begin{array}{l}\text { C H A R M - } \\
\text { P r e s e r v e d } \\
\text { Trial }^{49}\end{array}$ & $\begin{array}{l}\text { Randomized } 3023 \text { patients between candesartan } \\
\text { and placebo, failed to demonstrate a significant } \\
\text { effect on cardiovascular death }\end{array}$ & $\begin{array}{l}\text { hospitalizations in the candesartan- } \\
\text { treated patients achieved only after } \\
\text { adjustment for non significant }\end{array}$ \\
\hline I-PRESERVE & The largest till date for HFpEF since it enrolled & differences in baseline characteristics \\
\hline Trial $^{50}$ & $\begin{array}{l}4128 \text { patients at least } 60 \text { years of age and had } \\
\text { an EF of at least } 45 \% \text { with New York Heart } \\
\text { Association Class II, III, or IV HF and randomly } \\
\text { assigned them to irbesartan or placebo. Mortality } \\
\text { or rates of hospitalizations for cardiovascular } \\
\text { causes were again not improved by treatment } \\
\text { with an ARB the Irbesartan. }\end{array}$ & \\
\hline $\begin{array}{l}\text { P E P - C H F } \\
\text { Trial }^{51}\end{array}$ & $\begin{array}{l}\text { Patients older than } 70 \text { years with chronic HF } \\
\text { and normal or near-normal EF were randomized } \\
\text { to perindopril (an ACE inhibitor) or placebo. } \\
\text { The results of the PEP-CHF study in contrary } \\
\text { to earlier SOLVD trial }{ }^{[52]} \text { reported no overall } \\
\text { difference in mortality and or need for HF } \\
\text { hospitalizations on the use of ACEI in HFrEF } \\
\text { patients }\end{array}$ & $\begin{array}{l}\text { Due to lower than anticipated enrollment } \\
\text { and event rates, and high rate of cessation } \\
\text { of blinded therapy, with crossover to } \\
\text { open-label ACE inhibitor use in both } \\
\text { groups the study had no enough power } \\
\text { to demonstrate significant reduction in } \\
\text { the primary endpoint. }\end{array}$ \\
\hline $\begin{array}{l}\text { S E N I O R S } \\
\text { Trial }^{53}\end{array}$ & $\begin{array}{l}\text { Tested the effect of the beta }- \text {-selective blocker } \\
\text { nebivolol with vasodilator property by virtue } \\
\text { of Nitric Oxide release in patients with HF. } \\
\text { There was a modest but significant reduction } \\
\text { in the primary endpoint of all-cause mortality } \\
\text { or cardiovascular hospitalizations, which was } \\
\text { driven primarily by the effect on hospitalizations } \\
\text { in prespecified subgroup with EF less than } 35 \% \\
\text { but did not detect any trends toward reduced } \\
\text { benefit in those with higher EF }\end{array}$ & $\begin{array}{l}\text { A major limitation of this study is that } \\
\text { it enrolled very few patients with EF } \\
\text { higher than } 50 \% \text { in the trial. }\end{array}$ \\
\hline $\begin{array}{ll}\text { Hong } & \text { Kong } \\
\text { diastolic } & \text { heart } \\
\text { failure study } & \end{array}$ & $\begin{array}{l}\text { Randomized } 150 \text { patients with HFpEF (EF } \\
>45 \% \text { ) to diuretics alone, diuretics plus } \\
\text { irbesartan, or diuretics plus ramipril. The end } \\
\text { points that were compared were Quality of life } \\
\text { assessment, 6-minute walk test, and Doppler } \\
\text { echocardiography were performed at baseline } \\
\text { and at } 12,24 \text {, and } 52 \text { weeks. The quality of life } \\
\text { score and 6-minute walk test increased similarly, } \\
\text { and hospitalizations were similar in all three } \\
\text { groups. }\end{array}$ & $\begin{array}{l}\text { There was modest improvements in } \\
\text { Doppler systolic and diastolic indices } \\
\text { and NT-proBNP levels in the irbesartan } \\
\text { and ramipril groups. }\end{array}$ \\
\hline
\end{tabular}

Multicenter, prospective, trial that randomized 422 ambulatory patients with chronic New York Heart ALDO-DHF Association class II or III heart failure, preserved left ALDO-DHF ventricular ejection fraction of $50 \%$ or greater, and evidence Trial $^{55}$ of diastolic dysfunction to spironolactone or placebo. Long-term aldosterone receptor blockade improved left ventricular diastolic function but did not affect maximal exercise capacity, patient symptoms, or quality of life in

Whether the improved left ventricular function observed in the Aldo-DHF trial is of clinical significance requires further investigation in larger populations. patients with heart failure with preserved ejection fraction. 


$\begin{array}{lll} & \begin{array}{l}\text { The results from RELAX } \\ \text { can lead to guideline }\end{array} \\ \text { R E L A X } & \begin{array}{l}\text { Chronic Phosphdiesterase-5 Inhibition (PDE5I) improves } \\ \text { exercise capacity in HFpEF patients, but not considered } \\ \text { a pivotal trial in labeling of sildenafil for the treatment of } \\ \text { Trial }{ }^{57} \text { recommendations for use of }\end{array} \\ & \begin{array}{l}\text { PDE5I to improve symptoms } \\ \text { in HFpEF and to an outcome- } \\ \text { based study of PDE5I in } \\ \text { HFpEF }\end{array}\end{array}$

\section{Non -Pharmacological measures:}

Daily monitoring of weight, attention to diet and lifestyle, patient education, and close medical follow-up.

- The role of exercise training in patients with HFpEF has also been explored, ${ }^{56}$ but lacks definitive benefits of exercise training in patients with HFpEF.

\section{Pharmacological measures:}

TABLE 2 - 2013 ACCF/AHA Guidelines for Recommendations for Treatment of HFpEF ${ }^{58}$

\section{CONCLUSION}

HFpEF is a novel entity that makes up about half of the overall HF burden. But the paradox is: morbidity and mortality in $\mathrm{HFpEF}$ despite being similar to patients with HFrEF, cardiology community is yet to offer the patients of HFpEF with mortality reducing treatment. Patients with HFpEF are usually older women with a history of hypertension. obesity, $\mathrm{CAD}$, diabetes mellitus, and atrial fibrillation are also highly prevalent in HFpEF. Diagnosis of HFpEF is an uphill task since it relies upon careful clinical evaluation, doppler (pulse wave and Tissue ) echocardiography, and invasive hemodynamic assessment after exclusion of potential non cardiac causes of symptoms suggestive of HF. Better

\begin{tabular}{|c|c|c|}
\hline CLASS & INDICATION & $\begin{array}{l}\text { LEVEL OF } \\
\text { EVIDENCE }\end{array}$ \\
\hline I (indicated) & $\begin{array}{l}\text { Systolic and diastolic blood pressure should be controlled } \\
\text { according to published clinical practice }\end{array}$ & B \\
\hline I & $\begin{array}{l}\text { Diuretics should be used for relief of symptoms due to } \\
\text { volume overload. }\end{array}$ & $\mathrm{C}$ \\
\hline $\begin{array}{l}\text { Ila (good } \\
\text { supportive } \\
\text { evidence) }\end{array}$ & $\begin{array}{l}\text { Coronary revascularization for patients with CAD in whom } \\
\text { angina or demonstrable myocardial ischemia is present } \\
\text { despite Guideline directed medical therapy. }\end{array}$ & $\mathrm{C}$ \\
\hline IIa & $\begin{array}{l}\text { Management of AF according to published clinical practice } \\
\text { guidelines for HFpEF to improve symptomatic HF. }\end{array}$ & $\mathrm{C}$ \\
\hline IIa & $\begin{array}{l}\text { Use of beta-blocking agents, ACE inhibitors, and ARBs for } \\
\text { hypertension in HFpEF. }\end{array}$ & $\mathrm{C}$ \\
\hline $\begin{array}{l}\text { IIb (weak } \\
\text { supportive } \\
\text { evidence) }\end{array}$ & $\begin{array}{l}\text { ARBs might be considered to decrease hospitalizations in } \\
\text { HFpEF. }\end{array}$ & B \\
\hline III(no benefit) & Nutritional supplementation is not recommended in HFpEF. & $\mathrm{C}$ \\
\hline
\end{tabular}

\section{FUTURE DIRECTIVES}

The future answers may be unearthed by a number of ongoing clinical trials in HFpEF, aldosterone antagonists (TOPCAT trial), atrial pacing (RESET trial), and baroreflex control devices (Rheos diastolic heart failure trial). understanding of HFpEF interms of pathophysiology, has opened doors for many research to bring the long awaited treatment modalities for HFpEF in day to day clinical practice. As "prevention is always better than cure" to recognize the co-morbidities and treat early on could prevent HFpEF. Cornerstone of treatment of this entity revolves around treatment of underlying cause and symptom guided therapy. 


\section{REFERENCES}

1. Sanderson JE. Heart failure with a normal ejection fraction. Heart. 2007;93:155-8.

2. McMurray J, Pfeffer MA. New therapeutic options in congestive heart failure: part II. Circulation. 2002;105:2223-8.

3. Sanderson JE, Gibson DG, Brown DJ, et al. Left ventricular filling in hypertrophic cardiomyopathy. An angiographic study. $\mathrm{Br}$ Heart J. 1977;39:661-70.

4. Hanrath P, Mathey DG, Siegert R, et al. Left ventricular relaxation and filling pattern in different forms of left ventricular hypertrophy: an echocardiographic study. Am J Cardiol. 1980;45:15-23.

5. Hess OM, Grimm J, Krayenbuehl HP. Diastolic simple elastic and viscoelastic properties of the left ventricle in man. Circulation. 1979;59:1178-87.

6. Soufer R, Wohlgelernter D, Vita NA, et al. Intact systolic left ventricular function in clinical congestive heart failure. Am J Cardiol. 1985;55:1032-36.

7. Aronow WS, Kronzon I. Effect of enalapril on congestive heart failure treated with diuretics in elderly patients with prior myocardial infarction and normal left ventricular ejection fraction. Am J Cardiol. 1993;71:602-4.

8. Carson P, Johnson G, Fletcher R, et al. Mild systolic dysfunction in heart failure (left ventricular ejection fraction .35\%): baseline characteristics, prognosis and response to therapy in the Vasodilator in Heart Failure Trials (V-HeFT). J Am Coll Cardiol. 1996;27:642-9.

9. Aronow WS, Ahn C, Kronzon I. Effect of propranolol vs. no propranolol on total mortality plus nonfatal myocardial infarction in older patients with prior myocardial infarction, congestive heart failure, and left ventricular ejection fraction $>$ or $=40 \%$ treated with diuretics plus angiotensin-converting enzyme inhibitors. Am J Cardiol. 1997;80:207-9.

10. Vasan RS, Levy D. Defining diastolic heart failure: a call for standardized diagnostic criteria. Circulation. 2000;101:2118-21.

11. Steinberg BA, Zhao X, Heidenreich PA, et al. Trends in Patients Hospitalized
With Heart Failure and PreservedLeft Ventricular Ejection Fraction: Prevalence, Therapies, and Outcomes. Circulation. 2012;126:65-75.

12. Owan TE, Hodge DO, Herges RM, et al. Trends in prevalence and outcome of heart failure with preserved ejection fraction. N Engl J Med. 2006;355:251-9.

13. Redfield MM. Heart failure with normal ejection fraction. In: Bonow RO, Mann DL, Zipes DP, Libby P, editor. Braunwald's Heart Disease A textbook of Cardiovascular Medicine. 9 ed: Elsevier Saunders; 2012. p. 586-600.

14. Owan TE, Redfield MM. Epidemiology of diastolic heart failure. Prog Cardiovasc Dis. 2005; 47:320.

15. Hogg K, Swedberg K, McMurray J. Heart failure with preserved left ventricular systolic function; epidemiology, clinical characteristics, and prognosis. J Am Coll Cardiol. 2004; 43:317.

16. Bhatia RS, Tu JV, Lee DS, et al. Outcome of heart failure with preserved ejection fraction in a population-based study. N Engl J Med. 2006; 355:260

17. Curtis JP, Sokol SI, Wang Y, et al. The association of left ventricular ejection fraction, mortality, and cause of death in stable outpatients with heart failure. J Am Coll Cardiol. 2003; 42:736.

18. Henkel DM, Redfield MM, Weston SA, et al. Death in heart failure: a community perspective. Circ Heart Fail. 2008;1:91.

19. Dunlay SM, Redfield MM, Weston SA, et al. Hospitalizations after heart failure diagnosis a community perspective. J Am Coll Cardiol. 2009;54:1695.

20. Smith GL, Masoudi FA, Vaccarino V, et al. Outcomes in heart failure patients with preserved ejection fraction: Mortality, readmission, and functional decline. J Am Coll Cardiol. 2003; 41:1510.

21. Paulus WJ, Tschope C, Sanderson JE, et al. How to diagnose diastolic heart failure: a consensus statement on the diagnosis of heart failure with normal left ventricular ejection fraction by the Heart Failure and Echocardiography Associations of the European Society of Cardiology. Eur Heart J. 2007;28:2539-50. 
22. Yu CM, Lin H, Yang H, et al. Progression of systolic abnormalities in patients with "isolated" diastolicheartfailureand diastolic dysfunction. Circulation. 2002;105:1195201.

23. Borlaug BA, Lam CS, Roger VL, et al. Contractility and ventricular systolic stiffening in hypertensive heart disease insights into the pathogenesis of heart failure with preserved ejection fraction. J Am Coll Cardiol. 2009;54:410-8.

24. Borlaug BA, Melenovsky V, Russell SD, et al. Impaired chronotropic and vasodilator reserves limit exercise capacity in patients with heart failure and a preserved ejection fraction. Circulation. 2006;114:2138-47.

25. Ennezat PV, Lefetz Y, Marechaux S, et al. Left ventricular abnormal response during dynamic exercise in patients with heart failure and preserved left ventricular ejection fraction at rest. J Card Fail. 2008;14:475-80.

26. Borlaug BA, Olson TP, Lam CS, et al. Global cardiovascular reserve dysfunction in heart failure with preserved ejection fraction. J Am Coll Cardiol. 2010;56:84554.

27. Phan TT, Abozguia K, Nallur Shivu G, et al. Heartfailure with preserved ejection fraction is characterized by dynamic impairment of active relaxation and contraction of the left ventricle on exercise and associated with myocardial energy deficiency. J Am Coll Cardiol. 2009;54:402-9.

28. Tan YT, Wenzelburger F, Lee E, et al. The pathophysiology of heart failure with normal ejection fraction: exercise echocardiography reveals complex abnormalities of both systolic and diastolic ventricular function involving torsion, untwist, and longitudinal motion. J Am Coll Cardiol. 2009;54:36-46.

29. Kawaguchi M, Hay I, Fetics B, et al. Combined ventricular systolic and arterial stiffening in patients with heart failure and preserved ejection fraction: implications for systolic and diastolic reserve limitations. Circulation. 2003;107:714-20.

30. Borlaug BA, Kass DA. Ventricularvascular interaction in heart failure. Heart Fail Clin. 2008;4:23-36.
31. Brubaker PH, Joo KC, Stewart KP, et al. Chronotropic incompetence and its contribution to exercise intolerance in older heart failure patients. J Cardiopulm Rehabil. 2006;26:86-9.

32. Kjaergaard J, Akkan D, Iversen KK, et al. Prognostic importance of pulmonary hypertension in patients with heart failure. Am J Cardiol. 2007;99:1146-50.

33. Lam CS, Roger VL, Rodeheffer RJ, Borlaug BA, et al. Pulmonary hypertension in heart failure with preserved ejection fraction: a communitybased study. J Am Coll Cardiol. 2009;53:1119-26.

34. Borlaug BA, Nishimura RA, Sorajja P, et al. Exercise hemodynamics enhance diagnosis of early heart failure with preserved ejection fraction. Circ Heart Fail. 2010;117:2051-60.

35. Borlaug BA, Paulus WJ. Heart failure with preserved ejection fraction: pathophysiology, diagnosis, and treatment. Eur Heart J. 2011 Mar;32(6):670-9.

36. Brucks S, Little WC, Chao T, Kitzman et al. Contribution of left ventricular diastolic dysfunction to heart failure regardless of ejection fraction. Am J Cardiol. 2005;95:603-6.

37. Fukuta H, Little WC. Contribution of systolic and diastolic abnormalities to heart failure with a normal and a reduced ejection fraction. Prog Cardiovasc Dis. 2007;49:229-40.

38. Wang J, Khoury DS, Yue Y, et al. Preserved left ventricular twist and circumferential deformation, but depressed longitudinal and radial deformation in patients with diastolic heart failure. Eur Heart J. 2008;29:1283-9.

39. BaicuCF,ZileMR,Aurigemma GP, etal.Left ventricular systolic performance, function, and contractility in patients with diastolic heart failure. Circulation. 2005;111:230612.

40. Melenovsky V, Borlaug BA, Rosen B, et al. Cardiovascular features of heart failure with preserved ejection fraction vs. nonfailing hypertensive left ventricular hypertrophy in the urban Baltimore community: the role of atrial remodeling/dysfunction. J Am Coll Cardiol. 2007;49:198-207. 
41. Guazzi M, Samaja M, Arena R, et al. Longterm use of sildenafil in the therapeutic management of heart failure. J Am Coll Cardiol. 2007;50:2136-44.

42. Clark AL, Poole-Wilson PA, Coats AJ. Exercise limitation in chronic heart failure: central role of the periphery. J Am Coll Cardiol. 1996;28:1092-102.

43. Lau E, Tang WHW. Heart failure with preserved ejection fraction and restrictive cardiomyopathy. In: Griffin BP, editor. Manual of cardiovascular medicine. 4 ed: Lippincott Williams and Wilkins; 2013. p. $150-9$

44. Mullens W, Borowski AG, Curtin RJ, et al. Tissue Doppler imaging in the estimation of intracardiac filling pressure in decompensated patients with advanced systolic heart failure. Circulation. 2009;119:62-70.

45. Handoko ML, Paulus WJ. Polishing the diastolic dysfunction measurement stick. Eur J Echocardiogr. 2008;9:575-7.

46. Kasner M, Westermann D, Steendijk P, et al. Utility of Doppler echocardiography and tissue Doppler imaging in the estimation of diastolic function in heart failure with normal ejection fraction: a comparative Doppler-conductance catheterization study. Circulation. 2007;116:637-47

47. Burgess MI, Jenkins C, Sharman JE, et al. Diastolic stress echocardiography: hemodynamic validation and clinical significance of estimation of ventricular filling pressure with exercise. J Am Coll Cardiol. 2006;47:1891-900.

48. Ahmed A, Rich MW, Fleg JL, et al. Effects of digoxin on morbidity and mortality in diastolic heart failure: The ancillary digitalis investigation group trial. Circ Heart Fail. 2006; 114:397.

49. Yusuf S, Pfeffer MA, Swedberg K, et al. Effects of candesartan in patients with chronic heart failure and preserved leftventricular ejection fraction: The CHARMPreserved Trial. Lancet. 2003; 362:777.

50. Massie BM, Carson PE, McMurray JJ, et al. Irbesartan in patients with heart failure and preserved ejection fraction. N Engl J Med. 2008; 359:2456.

51. Cleland JG, Tendera M, Adamus J, et al. The perindopril in elderly people with chronic heart failure (PEP-CHF) study. Eur Heart J. 2006; 27:2338.

52. SOLVD-Investigators. Effect of enalapril on survival in patients with reduced left ventricular ejection fractions and congestive heart failure. N Engl J Med. 1991;325:293-302.

53. Flather MD, Shibata MC, Coats AJ, et al. Randomized trial to determine the effect of nebivolol on mortality and cardiovascular hospital admission in elderly patients with heart failure (SENIORS). Eur Heart J. 2005; 26:215.

54. Yip GW, Wang M, Wang T, et al. The Hong Kong diastolic heart failure study: A randomised controlled trial of diuretics, irbesartan and ramipril on quality of life, exercise capacity, left ventricular global and regional function in heart failure with a normal ejection fraction. Heart. 2008; 94:573.

55. Edelmann F, Wachter R, Schmidt AG. Effect of spironolactone on diastolic function and exercise capacity in patients with heart failure with preserved ejection fraction: the Aldo-DHF randomized controlled trial. JAMA. 2013;309:781-91.

56. Pina IL, Apstein CS, Balady GJ, et al. Exercise and heart failure: A statement from the American Heart Association Committee on exercise, rehabilitation, and prevention. Circ Heart Fail. 2003; 107:1210.

57. Redfield MM, Chen HH, Borlaug BA, et al. Effect of phosphodiesterase-5 inhibition on exercise capacity and clinical status in heart failure with preserved ejection fraction: a randomized clinical trial. JAMA. 2013;309:1268-77.

58. Yancy CW, Jessup M, Bozkurt B. 2013 ACCF/AHA guideline for the management of heart failure: a report of the American College Of Cardiology Foundation/ American Heart Association task force on practice guidelines. Circulation. 2013 Oct $15 ; 128(16): 1810-52$. 